\title{
Spectroscopic Characterization of an Extensive Set of c-Type Peptide Fragment lons Formed by Electron Transfer Dissociation Suggests Exclusive Formation of Amide Isomers
}

\author{
Lisanne J. M. Kempkes, ${ }^{\dagger}$ Jonathan Martens, $^{\dagger}{ }^{\circledR}$ Giel Berden, ${ }^{\dagger}{ }^{\dagger}$ and Jos Oomens, ${ }^{*},,^{\ddagger}(0)$ \\ ${ }^{\dagger}$ FELIX Laboratory, Institute for Molecules and Materials, Radboud University, Toernooiveld 7, 6525 ED Nijmegen, The \\ Netherlands \\ ${ }^{*}$ Van't Hoff Institute for Molecular Sciences, University of Amsterdam, Science Park 904, 1098 XH Amsterdam, The Netherlands
}

Supporting Information

ABSTRACT: Electron attachment dissociation (electron capture dissociation (ECD) and electron transfer dissociation (ETD)) applied to gaseous multiply protonated peptides leads predominantly to backbone $\mathrm{N}-\mathrm{C}_{\alpha}$ bond cleavages and the formation of $c$ - and $z$-type fragment ions. The mechanisms involved in the formation of these ions have been the subject of much discussion. Here, we determine the molecular structures of an extensive set of $c$-type ions produced by ETD using infrared ion spectroscopy. Nine $c_{3}$ - and $c_{4}$-ions are investigated to establish their C-terminal structure as either enol-imine or amide isomers by comparison of the experimental infrared spectra with quantum-chemically predicted spectra for both structural variants. The spectra suggest that all $c$-ions investigated possess an amide structure; the absence of the $\mathrm{NH}$ bending mode at approximately $1000-1200 \mathrm{~cm}^{-1}$ serves as an important diagnostic feature.

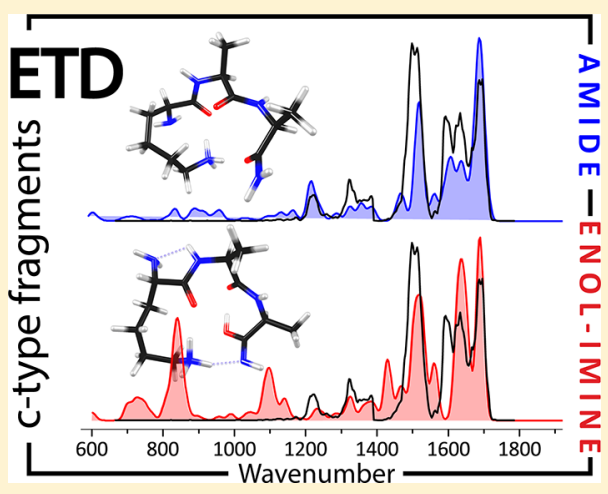

$\mathrm{M}$ ass spectrometry (MS) is well-established as the leading technique for protein sequencing. ${ }^{1}$ Collision induced dissociation (CID) has long been the main tandem MS (MS/ MS) method used to induce peptide fragmentation, cleaving protonated peptides at their amide bonds ${ }^{2}$ and generating predominantly $b$ - and $y$-type sequence ions. ${ }^{3}$ However, the inability of CID MS/MS to sequence labile post translational modifications (PTMs) and its limited applicability in top-down protein sequencing $^{4-9}$ have led to an increase in the use of fragmentation strategies based on electron attachment to the multiply protonated target, in particular electron capture dissociation (ECD) and electron transfer dissociation (ETD). ${ }^{10}$ ECD and ETD, jointly termed $\mathrm{ExD}$, increase sequence coverage and thus enable top-down sequencing, mitigating the need for enzymatic digestion of a protein into smaller peptides, $5,11-24$ and moreover leave labile PTMs attached, which was originally suggested to be due to a nonergodic nature of the dissociation process, but this hypothesis was later rejected. ${ }^{25-27} \mathrm{ExD}$ of multiply charged gaseous proteins results mainly in $c$ - and $z$-type ions, cleaving the backbone at the $\mathrm{N}-\mathrm{C}_{\alpha}$ bond. $^{24,28-35}$ Complementary information is obtained by combining $\mathrm{CID}$ and $\mathrm{ExD}$ for protein identification as different ion types are formed.

In ETD, an anionic species (often the radical anion of fluoranthene $\mathrm{e}^{10}$ ) is guided into the ion trap and stored along with the multiply protonated precursor peptide ion of interest. ${ }^{11,24,36} \mathrm{An}$ ion/ion reaction results in electron transfer and charge-reduction of the peptide ion forming a radical species. ${ }^{37}$ The charge recombination induces cleavage of the peptide backbone predominantly at the $\mathrm{N}-\mathrm{C}_{\alpha}$ bonds, ${ }^{24,28-35}$ resulting in $c$ - and radical $z$-type sequence ions.

The precise reaction mechanisms of ETD have been the subject of extensive discussion..$^{27,29,30,24,38-53}$ Several mechanisms have been proposed, with the Cornell ${ }^{29,39,44,54}$ and Utah-Washington ${ }^{40,45-48,55-57}$ mechanisms being the most prominent ones. In the Cornell mechanism, electron attachment occurs at a protonated site that is hydrogen-bonded to a nearby carbonyl. ${ }^{44}$ Hydrogen atom transfer from the now neutralized protonation site to the carbonyl group then induces $\mathrm{N}-\mathrm{C}_{\alpha}$ bond cleavage and the formation of $c$-type ions with an enol-imine structure at their C-terminal end (Scheme 1). In the Utah-Washington hypothesis, the electron is captured in the $\pi^{*}$-orbital of an amide carbonyl $\mathrm{H}$-bonded to a protonated site, producing a charge-stabilized amide anion-radical intermediate, which isomerizes by proton transfer to the peptide bond amide oxygen or nitrogen; ${ }^{34,58}$ proton transfer to the amide nitrogen upon cleavage of the $\mathrm{N}-\mathrm{C}_{\alpha}$ bond forms $c$ type ions with an amide moiety at the $\mathrm{C}$-terminus. Charge stabilization by protonation, rather than by metal-ion coordination, was recently suggested to enhance the efficiency of $c$ - and $z$-type ion formation. ${ }^{53}$

Because the two mechanisms lead to two different (isomeric) product ions, with either an enol-imine or an amide terminus, identification of the molecular structure of the

Received: September 16, 2018

Accepted: October 18, 2018

Published: October 22, 2018 
Scheme 1. Schematic Representation of Two Isomeric c-Type Product Ions That Have Been Proposed to Be Formed upon ETD $^{a}$

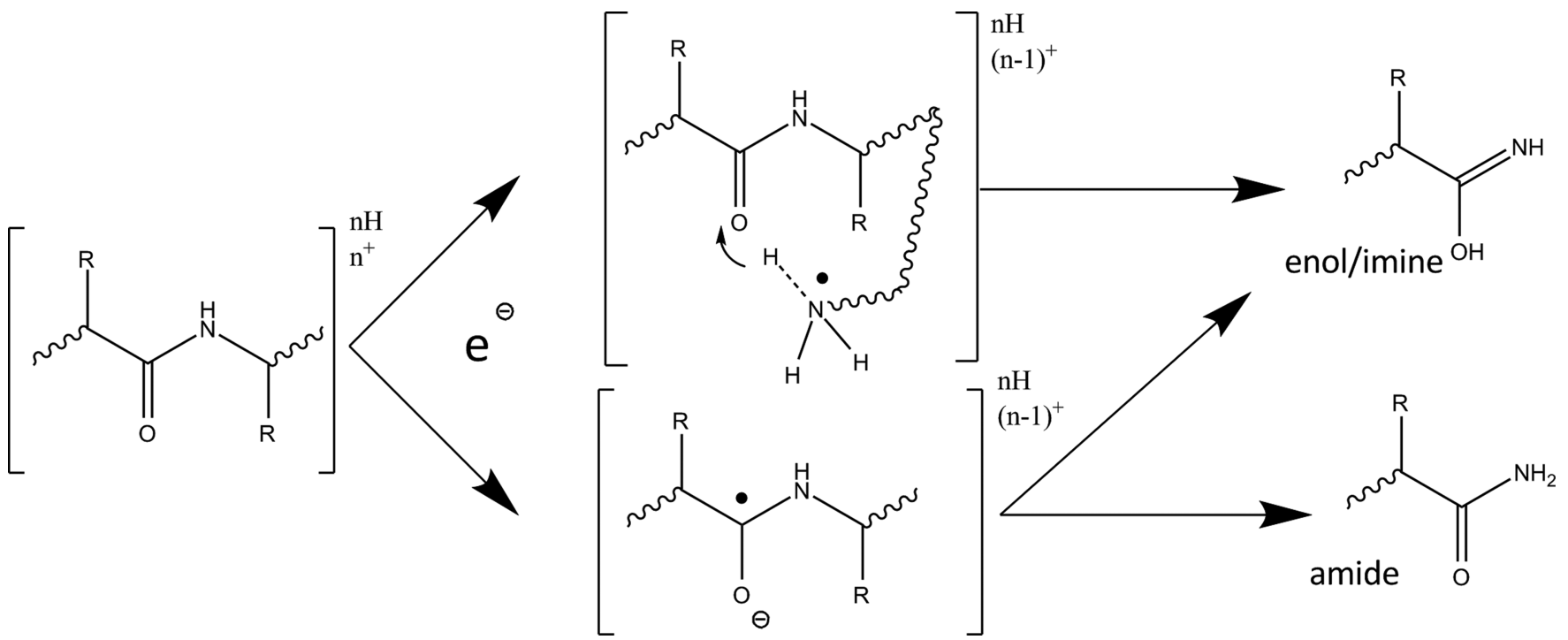

${ }^{a}$ The top structure is the enol-imine $c$-type structure proposed to result from the Cornell mechanism. Following the Utah-Washington mechanism, $c$-type product ions can form as either an amide or enol-imine.

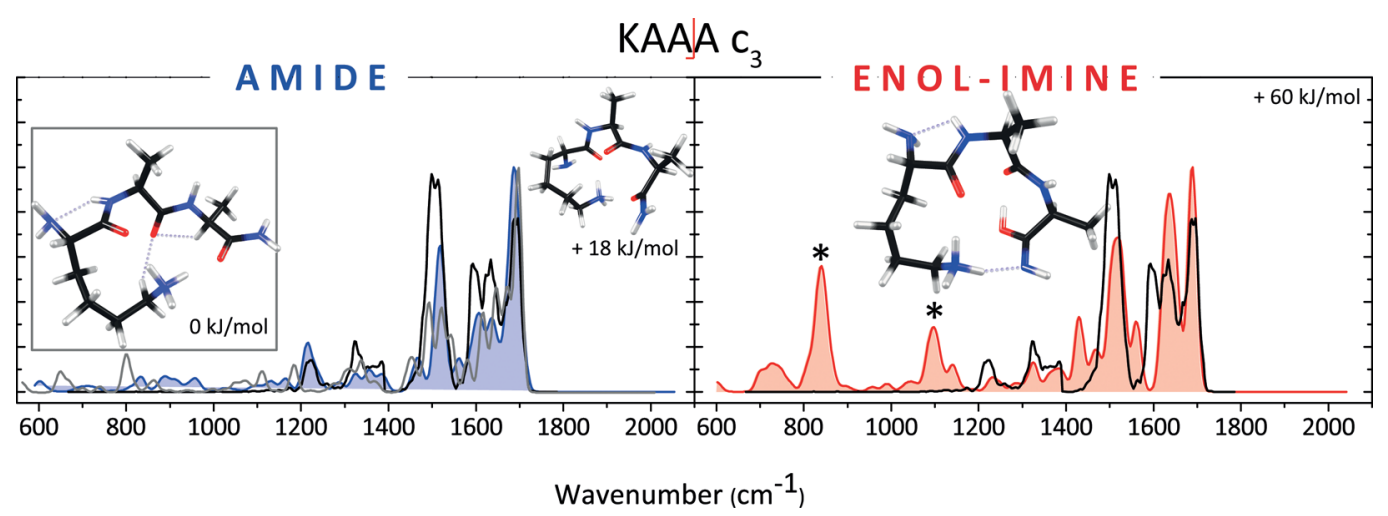

Figure 1. Experimental infrared spectrum of the ETD-generated $c_{3}$-ion from $[\mathrm{KAAA}+2 \mathrm{H}]^{2+}$ (in black) compared with computed spectra for the lowest-energy amide structure (left, gray), a higher-energy conformation of the amide isomer (left, blue), and the lowest-energy enol-imine structure (red, right). The experimental spectrum is assigned as an amide structure based on the generally favorable overlap between the experimental and computed spectrum in blue and in particular on the absence of $\mathrm{O}-\mathrm{H}$ and $\mathrm{N}-\mathrm{H}$ bending modes in the experimental spectra, diagnostic for the enol-imine structure (indicated with asterisks on the right).

$c$-type ions may shed light on their mechanism of formation. The combination of mass spectrometry, ion spectroscopy, and quantum-chemical calculations has become a powerful method for distinguishing isomers, tautomers, and conformers of MS/ MS reaction products, ${ }^{59-64}$ which has previously been used for the structural characterization of an ECD-generated $c_{0}$-ion of a derivatized peptide. ${ }^{65}$ Its structure was established to include an amide moiety as its C-terminus. More recently, the $c_{4}$-ion produced by ETD on the doubly protonated GL*GGK peptide was also assigned as an amide structure on the basis of ultraviolet photodissociation and infrared multiple photon dissociation (IRMPD) spectroscopy experiments along with density functional theory (DFT) calculations. Calculated spectra distinguished the amide tautomer from the enolimine tautomer by strong IR bands of the enol-imine product ion at $1040-1050 \mathrm{~cm}^{-1}$ and $1190-1220 \mathrm{~cm}^{-1}$, which were absent in the experimental spectrum. ${ }^{66}$

Ion mobility has also been used to characterize ETD fragment ions $\left(c_{3}, c_{4}, z_{3}\right.$, and $z_{4}$ of $\left.[\text { AAHAL }+2 \mathrm{H}]^{2+}\right){ }^{67}$
Although the collisional cross sections $(\Omega)$ showed close agreement with calculations, the values for enol-imine and amide tautomers were nearly identical, not allowing the authors to distinguish between them. In another study, the CID fragmentation pattern of the $c_{5}$-ion of GAILKGAILR was found to be essentially identical to that of the synthesized $\left[\text { GAILK- } \mathrm{NH}_{2}+\mathrm{H}\right]^{+}$analog. ${ }^{68}$ In contrast, CID fragmentation of the intact peptide $[\mathrm{GAILK}+\mathrm{H}]^{+}$showed a $y_{3}$-fragment ion and several neutral loss-species, which were absent in the CID spectrum of the $c_{5}$-ion (and of [GAILK- $\left.\mathrm{NH}_{2}+\mathrm{H}\right]^{+}$).

Here we address the question of whether the formation of amide $c$-type ions is generic or not by applying IRMPD spectroscopy to probe the structure of an extensive set of ETD $c$-type ions. This also addresses the question of whether the fragment ion structure is influenced by the identity of the amino acid residue at the cleavage site. Peptides containing a Lys residue at the $\mathrm{N}$-terminus were selected to favor $c$-ion formation upon ETD. The peptide length is varied (tetra- and heptapeptides), as is the amino acid residue $\mathrm{N}$-terminal to 
cleavage site (Ala, His, or Phe); a peptide with a His residue Cterminal to the cleavage site was also included. An IRMPD spectrum was also recorded for the $\mathrm{NH}_{2}$ capped peptide of AAAA, as reference for an amide-structure $c$-type ion.

Figure 1 presents the IRMPD spectrum of the $c_{3}$ ion of $[\mathrm{KAAA}+2 \mathrm{H}]^{2+}$ compared with spectra predicted for different structural variants by DFT. The gray trace in the left panel is the computed spectrum for the lowest-energy conformer found for the amide isomeric form. The spectrum in blue represents an alternative, higher-energy $(+18 \mathrm{~kJ} / \mathrm{mol})$ conformer of the same amide isomer. The right panel compares the IRMPD spectrum with the predicted spectrum for the lowest-energy conformer of the enol-imine isomer, which lies $60 \mathrm{~kJ} / \mathrm{mol}$ above the lowest-energy amide conformer.

In the calculated enol-imine spectrum, two relatively strong diagnostic bands $(*)$ are due to $\mathrm{NH}$ bending of the enol-imine moiety $\left(1100 \mathrm{~cm}^{-1}\right)$ and to a delocalized bending vibration involving enol-imine $\mathrm{NH}$ and $\mathrm{OH}$ bonds $\left(840 \mathrm{~cm}^{-1}\right)$. In the computed spectrum for the amide isomer, no strong bands are predicted at these frequencies. The observation that the experimental spectrum shows little or no intensity at these frequencies suggests that the $c_{3}$-ion possesses an amide structure. The remainder of the experimental spectrum between 1200 and $1750 \mathrm{~cm}^{-1}$ also shows good agreement with the spectrum predicted for the amide isomer, especially for the conformer at slightly elevated energy (blue trace).

This isomeric structure assignment is in line with that for two $c$-type $\mathrm{ExD}$ fragments studied by IR spectroscopy previously. ${ }^{65,66}$ Ref 65 addresses the structure of a (modified) $c_{0}$-ion, so that the two isomeric product ions can conveniently be distinguished based on the absence or presence of the amide $\mathrm{C}=\mathrm{O}$ stretch $\left(\right.$ at $\left.1731 \mathrm{~cm}^{-1}\right)$. The enol-imine structure does not possess a carbonyl moiety so that its predicted spectrum does not contain a $\mathrm{C}=\mathrm{O}$ stretch band. The longer $c_{3}$ and $c_{4}$ ions studied in the present work possess multiple amide $\mathrm{C}=\mathrm{O}$ moieties, one for each peptide linkage, so that the presence or absence of a carbonyl stretch is no longer a good diagnostic. Instead, the presence of the $\mathrm{NH}$ bending mode near $1100 \mathrm{~cm}^{-1}$ is used here as a diagnostic for the enol-imine structure. $^{66}$

Peptides with a C-terminal $\mathrm{NH}_{2}$-cap are readily available and can serve as a reference for $c$-type fragment ions in the amide isomeric configuration. ${ }^{65,66,68,69}$ The IRMPD spectrum of protonated $\mathrm{NH}_{2}$-capped tetra-alanine, $\left[\text { AAAA- } \mathrm{NH}_{2}+\mathrm{H}\right]^{+}$, is shown in Figure 2. The band near $1700 \mathrm{~cm}^{-1}$ is due to $\mathrm{C}=\mathrm{O}$ stretches of the first and last peptide linkages, with the

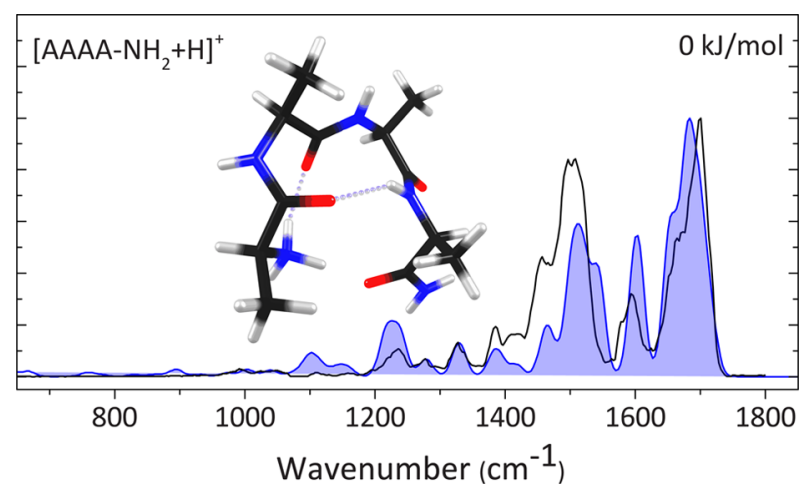

Figure 2. Experimental spectrum of $\mathrm{NH}_{2}$-capped AAAA compared with the computed spectrum for a $\mathrm{N}$-terminally protonated structure. shoulder at $1670 \mathrm{~cm}^{-1}$ being due to a combined $\mathrm{C}=\mathrm{O}$ stretch with $\mathrm{N}-\mathrm{H}$ bending at the $\mathrm{N}$-terminus of the peptide. The peak at $1600 \mathrm{~cm}^{-1}$ corresponds to $\mathrm{NH}$ bending at the protonated $\mathrm{N}$ terminus, and that around $1500 \mathrm{~cm}^{-1}$ corresponds to modes with combined backbone $\mathrm{NH}$ and terminal $\mathrm{NH}_{3}$ bending character. Clearly, matching this feature with theory appears slightly more challenging than the other bands, which we shall keep in mind in our analysis below.

Relying on the good overall match between experiment and theory in Figure 2 and having established the salient distinguishing features between amide and enol-imine IR spectra, we extend our study to a large set of $c_{3}$ and $c_{4}$ ions generated from different precursor peptides. Figure 3 shows the experimental IRMPD spectra of eight different $c_{3}$ and $c_{4}$ ions obtained from ETD on doubly protonated KAHA, KAAAAAA, KAAHAAA, KAHAAAA, and KAFAAAA. All experimental spectra are compared with the calculated spectra for both the enol-imine and the amide isomer, including different conformations of these isomers. In Figure 3, the left panels compare experimental spectra with computed spectra for amide isomers, with the best matching spectra in shaded blue and, if different, the most stable conformer in gray. The panels on the right show the predicted spectra for the alternative enol-imine isomers of each of the $c$-ions overlaid on the same experimental spectra; diagnostic $\mathrm{NH}$ and $\mathrm{OH}$ bending modes are indicated by asterisks. The spectrum for the lowest-energy conformer is shown in all cases.

The $c_{3}$-ions of KAHAAAA and of KAHA likely are identical, which is indeed confirmed by their IR spectra (see Figure S1 in the Supporting Information). The computed spectra in the first and fifth row of Figure 3 are therefore identical. Similarly, the $c_{3}$-ions of KAAA and KAAHAAA are also the same as suggested by an overlay of their IR spectra in Figure S1; the computed spectra in Figure 1 and on the third row of Figure 3 are therefore identical.

For all structures, the preferred protonation site is the Lys side chain, except for the $c_{4}$-ions of KAAHAAA and KAHAAAA, where protonation occurs on the His residue for the enol-imine isomers. The amide structure of KAHAAAA- $\mathrm{c}_{4}$ is also protonated at the $\mathrm{His}$ residue. Some enol-imine conformers converge to a structure where the proton has transferred from the Lys or His side chain to the imine nitrogen. As a consequence, their calculated spectra do not possess the typical $\mathrm{NH}$ bending modes. The match with the experimental spectra is poor, as shown in Figure S2, and we discard these structures.

All spectra feature prominent amide I (backbone amide carbonyl stretching around $1600-1700 \mathrm{~cm}^{-1}$ ) and amide II (backbone amide $\mathrm{NH}$ bending around $1500 \mathrm{~cm}^{-1}$ ) bands. The spectra in the $1400-1700 \mathrm{~cm}^{-1}$ range are generally well reproduced by the computed spectra for the amide isomers in blue except for some deviations in intensity for amide II in a few cases, as already noted for the $\mathrm{NH}_{2}$-capped $\mathrm{Ala}_{4}$ reference (Figure 2). As for the $c_{3}$ ion of KAAA in Figure 1, the lowestenergy conformer does not always provide the best match; for the $c_{4}$-ions of KAAAAAA and KAAHAAA, the spectral match is better for higher-energy conformers, which we tentatively attribute to kinetic trapping.

As compared to the amide spectra, the calculated spectra for the enol-imine isomers qualitatively display more prominent deviations from experiment in the $1400-1700 \mathrm{~cm}^{-1}$ range, with for instance significant mismatches in the amide I band (e.g., $\mathrm{KAH}-\mathrm{c}_{3}, \mathrm{KAA}-\mathrm{c}_{3}$, and $\mathrm{KAAH}-\mathrm{c}_{4}$ ) and the absence of the 


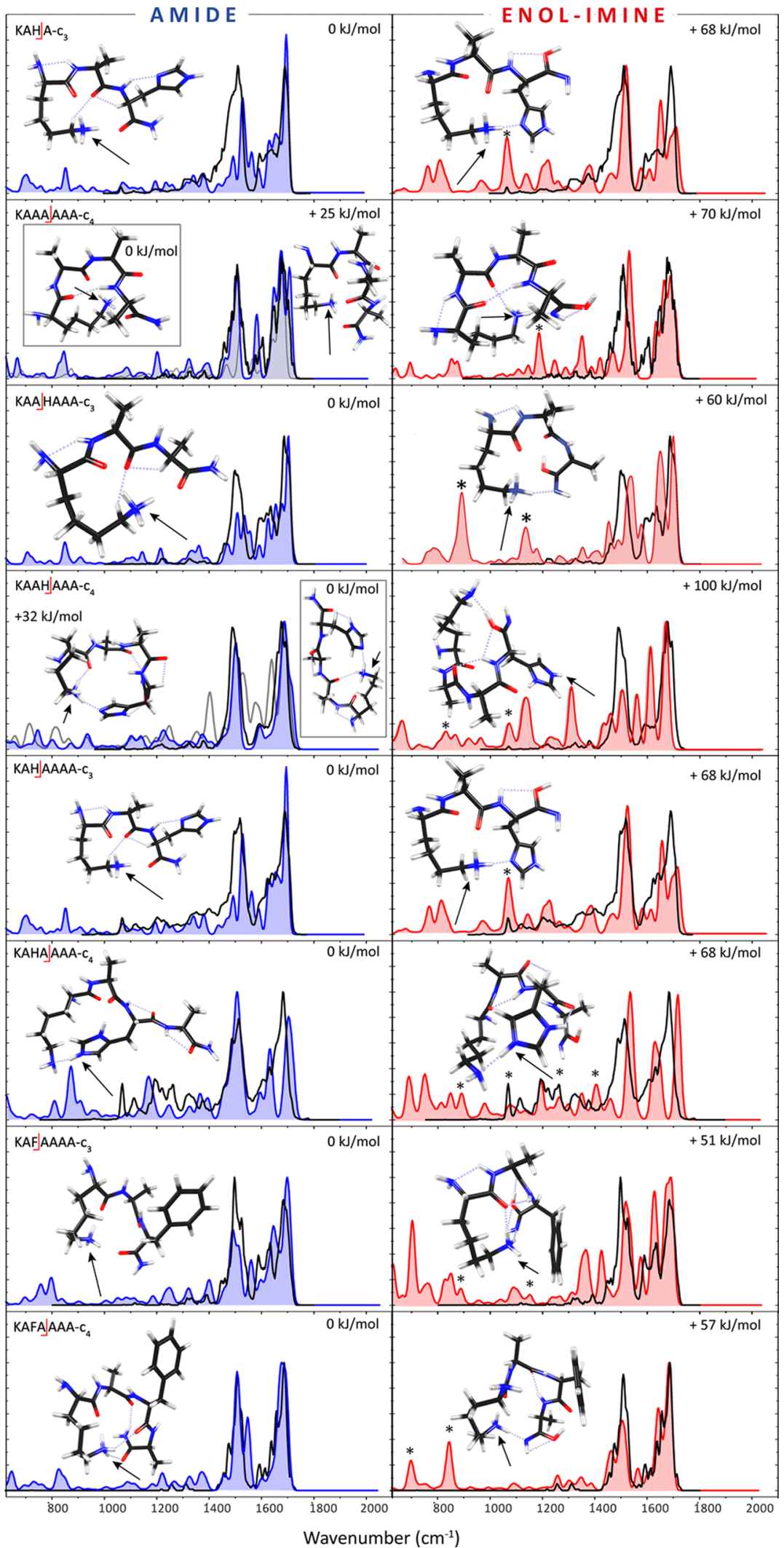

Figure 3. Experimental spectra of a series of $c_{3}$ and $c_{4}$ ETD fragment ions (black) compared with the computed spectra for the amide structures (left, blue) and for the enol-imine isomers (red, right). The stars indicate the enol-imine $\mathrm{NH}$ and $\mathrm{OH}$ bending modes. Arrows indicate the protonation site. For the $c_{4}$-ions of KAAAAAA and KAAHAAA, the best match is found for a higher-energy conformer; the spectrum of the lowestenergy amide conformer is shown in addition in light gray in these cases.

$1590 \mathrm{~cm}^{-1}$ band for KAAA-c 4 . Also at lower frequencies, amide spectra appear to provide an overall closer agreement than enol-imine spectra, with the general absence of the enol-imine $\mathrm{NH}$ and $\mathrm{OH}$ bending modes $(*)$ in the experimental spectra as 
specific examples. The overall picture that emerges from the comparisons in Figure 3 is that the amide isomer spectra provide the best match to the experimental spectra.

The enol-imine structures of interest here are between 51 and $100 \mathrm{~kJ} / \mathrm{mol}$ higher in energy than the global minimum amide structures, which is in line with relative energies reported previously. ${ }^{65,67,70,71}$ Although the IR spectra suggest an amide structure for all $c$-ions studied here, we cannot exclude the possibility that the amide structure is formed via an enol-imine intermediate, driven by the substantial gain in energy. The energetic barriers involved in such transformations have been investigated by transition-state (TS) calculations, and it appears likely that isomerization occurs before the incipient $c$ - and $z$-fragments separate. ${ }^{70,71}$ The charge-solvating behavior of the $z$-fragment in this predissociation ionmolecule complex lowers the barriers for the $\mathrm{H}$-atom transfer and can be regarded as a catalyst for the isomerization. ${ }^{70}$ The actual TS energies depend on the specific system but are in all cases much lower than the energy available from the charge recombination process. ${ }^{72}$

In conclusion, on the basis of our structural assignments from IR spectral matching in Figures 1 and 3 and the corresponding computed relative energies, this study suggests that for a set of nine $c$-type ions, all most likely possess an amide $\mathrm{C}$-terminus. Assuming the set of sequences selected for the precursor peptides is sufficiently diverse to be generally representative for a broader range of peptides, these results suggest $c$-type ions not having $\mathrm{C}$-terminal amide groups would be unusual and that they generally are $\mathrm{NH}_{2}$-capped truncated peptides. One caveat may be the presence of a Lys residue in all systems studied here. On the basis of computational investigations, the ammonium group of a protonated Lys side chain was suggested to catalyze the enol-imine to amide tautomerization. ${ }^{11}$ However, isolated cases of $c$-ions not including a Lys residue have been spectroscopically investigated and gave evidence for amide structures without exceptions. $^{65,66,73}$ The bottom line here is that the enolimine structure was not encountered in any of the spectroscopic investigations thus far. These experiments do not exclude the possibility that enol-imine structures are traversed as reaction intermediates but may be regarded as experimental evidence for their efficient conversion to amide structures. $^{70,71}$

\section{EXPERIMENTAL AND COMPUTATIONAL METHODS}

IRMPD Spectroscopy. The experiments made use of a modified ion trap tandem mass spectrometer (Bruker AmaZon ETD Speed) coupled to the beamline of the IR free electron laser FELIX. $^{59}$ Doubly protonated peptide ions were generated using electrospray ionization (ESI) from $10^{-6} \mathrm{M}$ solutions in $50: 50$ acetonitrile:water with $\sim 0.5 \%$ formic acid. The doubly charged precursor ions of interest were mass isolated in the quadrupole ion trap. ETD was effected by admitting fluoranthene radical anions ${ }^{37}$ to the trap reacting with the stored peptide cations for $300 \mathrm{~ms}$. The basic Lys residue in the first position generates a prominent series of $c$-type ions, out of which the singly charged $c_{3}$ or $c_{4}$ ion of interest was mass isolated. Note that Lys is preferred over other basic residues such as Arg or His because of its relative silence in the IR spectrum, in contrast with the guanidinium and imidazolium side chains which feature strong IR absorptions overlapping with, and therefore obscuring, the diagnostic amide I and II features in the spectra. A potential side effect of this choice is the alleged catalytic behavior of the ammonium group in the conversion of enol-imine to amide structures. ${ }^{71}$

The $c$-type fragment ion was then irradiated with two IR pulses of the FELIX free-electron laser. FELIX produced $6 \mu \mathrm{s}$ long macropulses of $20-60 \mathrm{~mJ}$ at a $10 \mathrm{~Hz}$ repetition rate having a bandwidth of $\sim 0.5 \%$ of the center frequency. The IRinduced dissociation yield, calculated as $\Sigma I$ (fragment ions)/ $\Sigma I$ (parent + fragment ions), at each laser frequency was determined from five averaged mass spectra. Plotting the yield as a function of laser frequency then generates an infrared spectrum. The yield is linearly corrected for the frequencydependent pulse energy, and the IR frequency is calibrated using a grating spectrometer.

Computational Chemistry. For all c-ions, enol-imine and amide isomeric structures were optimized, and their infrared spectra were calculated using DFT at the B3LYP/6-31++ $\mathrm{G}(\mathrm{d}, \mathrm{p})$ level using Gaussian 09 revision D01. ${ }^{74}$ These spectra were used for qualitative initial comparison with the experimental spectra. A molecular mechanics/molecular dynamics (MM/MD) approach employing AMBER $12^{75}$ was then used to further search for lower-energy conformers of both isomeric motifs. Within AMBER, an initial MM geometry optimization was performed, followed by a simulated annealing procedure up to $273-500 \mathrm{~K}$, resulting in 500 structures. These structures were grouped based on rms atom positions to give 20-30 candidate structures, which were optimized using DFT at the B3LYP/6-31++G(d,p) level. Their spectra were compared with the experimental spectra. Computed harmonic vibrational frequencies were scaled by 0.975 and convoluted with a $25 \mathrm{~cm}^{-1}$ full-width-at-half-maximum (fwhm) Gaussian line shape. Single-point electronic energies were calculated at the MP2/6-311+G(2d,2p) level using the B3LYP/6-31+ $+\mathrm{G}(\mathrm{d}, \mathrm{p})$ optimized structures. The computational procedure is described in more detail elsewhere. ${ }^{59,60,76}$

\section{ASSOCIATED CONTENT}

\section{S Supporting Information}

The Supporting Information is available free of charge on the ACS Publications website at DOI: 10.1021/acs.jpclett.8b02850.

Additional figures showing a comparison between the $c_{3}$ ions of doubly protonated KAHA and KAHAAAA (Figure S1) and the calculated spectra of alternative enol-imine structures in which the proton has transferred from the Lys or His side chain to the imine nitrogen atom (Figure S2); calculated relative Gibbs energies for all presented $c$-ion structures at three different levels of theory (Table S1) (PDF)

\section{AUTHOR INFORMATION}

\section{Corresponding Author}

*E-mail: j.oomens@science.ru.nl.

ORCID

Jonathan Martens: 0000-0001-9537-4117

Giel Berden: 0000-0003-1500-922X

Jos Oomens: 0000-0002-2717-1278

Notes

The authors declare no competing financial interest. 


\section{ACKNOWLEDGMENTS}

We gratefully acknowledge the Nederlandse Organsiatie voor Wetenschappelijk Onderzoek (NWO) for the support of the FELIX Laboratory. Financial support for this project was provided by NWO Chemical Sciences under VICI project nr. 724.011.002. The authors also thank NWO Physical Sciences (EW) and the SurfSARA Supercomputer Center for providing the computational resources under Rekentijd Grant no. 16327.

\section{REFERENCES}

(1) Hunt, D. F.; Yates, J. R.; Shabanowitz, J.; Winston, S.; Hauer, C. R. Protein Sequencing by Tandem Mass Spectrometry. Proc. Natl. Acad. Sci. U. S. A. 1986, 83, 6233-6237.

(2) Wells, M. J.; McLuckey, S. A. Collision-Induced Dissociation (CID) of Peptides and Proteins. Methods Enzymol. 2005, 402, 148185.

(3) Paizs, B.; Suhai, S. Fragmentation Pathways of Protonated Peptides. Mass Spectrom. Rev. 2005, 24, 508-548.

(4) Cooper, H. J.; Håkansson, K.; Marshall, A. G. The Role of Electron Capture Dissociation in Biomolecular Analysis. Mass Spectrom. Rev. 2005, 24, 201-222.

(5) Wiesner, J.; Premsler, T.; Sickmann, A. Application of Electron Transfer Dissociation (Etd) for the Analysis of Posttranslational Modifications. Proteomics 2008, 8, 4466-4483.

(6) Mirgorodskaya, E.; Roepstorff, P.; Zubarev, R. A. Localization of O-Glycosylation Sites in Peptides by Electron Capture Dissociation in a Fourier Transform Mass Spectrometer. Anal. Chem. 1999, 71, 4431-4436.

(7) Stensballe, A.; Jensen, O. N.; Olsen, J. V.; Haselmann, K. F.; Zubarev, R. A. Electron Capture Dissociation of Singly and Multiply Phosphorylated Peptides. Rapid Commun. Mass Spectrom. 2000, 14, 1793-1800.

(8) Håkansson, K.; Cooper, H. J.; Emmett, M. R.; Costello, C. E.; Marshall, A. G.; Nilsson, C. L. Electron Capture Dissociation and Infrared Multiphoton Dissociation MS/MS of an N-Glycosylated Tryptic Peptide to Yield Complementary Sequence Information. Anal. Chem. 2001, 73, 4530-4536.

(9) Mikesh, L. M.; Ueberheide, B.; Chi, A.; Coon, J. J.; Syka, J. E. P.; Shabanowitz, J.; Hunt, D. F. The Utility of ETD Mass Spectrometry in Proteomic Analysis. Biochim. Biophys. Acta, Proteins Proteomics 2006, 1764, 1811-1822.

(10) Riley, N. M.; Coon, J. J. The Role of Electron Transfer Dissociation in Modern Proteomics. Anal. Chem. 2018, 90, 40-64.

(11) Coon, J. J. Collisions or Electrons? Protein Sequence Analysis in the 21st Century. Anal. Chem. 2009, 81, 3208-3215.

(12) Swaney, D. L.; McAlister, G. C.; Coon, J. J. Decision TreeDriven Tandem Mass Spectrometry for Shotgun Proteomics. Nat. Methods 2008, 5, 959-964.

(13) Breuker, K.; McLafferty, F. W. Native Electron Capture Dissociation for the Structural Characterization of Noncovalent Interactions in Native Cytochrome C. Angew. Chem., Int. Ed. 2003, 42, 4900-4904.

(14) Breuker, K.; Oh, H.; Lin, C.; Carpenter, B. K.; McLafferty, F. W. Nonergodic and Conformational Control of the Electron Capture Dissociation of Protein Cations. Proc. Natl. Acad. Sci. U. S. A. 2004, 101, 14011-14016.

(15) Oh, H.; Breuker, K.; Sze, S. K.; Ge, Y.; Carpenter, B. K.; McLafferty, F. W. Secondary and Tertiary Structures of Gaseous Protein Ions Characterized by Electron Capture Dissociation Mass Spectrometry and Photofragment Spectroscopy. Proc. Natl. Acad. Sci. U. S. A. 2002, 99, 15863-15868.

(16) Breuker, K.; McLafferty, F. W. Stepwise Evolution of Protein Native Structure with Electrospray into the Gas Phase, $10^{-12}$ to $10^{2} \mathrm{~s}$. Proc. Natl. Acad. Sci. U. S. A. 2008, 105, 18145-18152.

(17) Horn, D. M.; Zubarev, R. A.; McLafferty, F. W. Automated De Novo Sequencing of Proteins by Tandem High-Resolution Mass Spectrometry. Proc. Natl. Acad. Sci. U. S. A. 2000, 97, 10313-10317.
(18) Coon, J. J.; Ueberheide, B.; Syka, J. E. P.; Dryhurst, D. D.; Ausio, J.; Shabanowitz, J.; Hunt, D. F. Protein Identification Using Sequential Ion/Ion Reactions and Tandem Mass Spectrometry. Proc. Natl. Acad. Sci. U. S. A. 2005, 102, 9463-9468.

(19) Kaplan, D. A.; Hartmer, R.; Speir, J. P.; Stoermer, C.; Gumerov, D.; Easterling, M. L.; Brekenfeld, A.; Kim, T.; Laukien, F.; Park, M. A. Electron Transfer Dissociation in the Hexapole Collision Cell of a Hybrid Quadrupole-Hexapole Fourier Transform Ion Cyclotron Resonance Mass Spectrometer. Rapid Commun. Mass Spectrom. 2008, 22, 271-278.

(20) Kelleher, N. L.; Zubarev, R. A.; Bush, K.; Furie, B.; Furie, B. C.; McLafferty, F. W.; Walsh, C. T. Localization of Labile Posttranslational Modifications by Electron Capture Dissociation: The Case of Г-Carboxyglutamic Acid. Anal. Chem. 1999, 71, 4250-4253.

(21) Chi, A.; Huttenhower, C.; Geer, L. Y.; Coon, J. J.; Syka, J. E. P.; Bai, D. L.; Shabanowitz, J.; Burke, D. J.; Troyanskaya, O. G.; Hunt, D. F. Analysis of Phosphorylation Sites on Proteins from Saccharomyces Cerevisiae by Electron Transfer Dissociation (ETD) Mass Spectrometry. Proc. Natl. Acad. Sci. U. S. A. 2007, 104, 2193-2198.

(22) Molina, H.; Horn, D. M.; Tang, N.; Mathivanan, S.; Pandey, A. Global Proteomic Profiling of Phosphopeptides Using Electron Transfer Dissociation Tandem Mass Spectrometry. Proc. Natl. Acad. Sci. U. S. A. 2007, 104, 2199-2204.

(23) Stephenson, J. L., Jr; McLuckey, S. A.; Reid, G. E.; Wells, J. M.; Bundy, J. L. Ion/Ion Chemistry as a Top-Down Approach for Protein Analysis. Curr. Opin. Biotechnol. 2002, 13, 57-64.

(24) Syka, J. E. P.; Coon, J. J.; Schroeder, M. J.; Shabanowitz, J.; Hunt, D. F. Peptide and Protein Sequence Analysis by Electron Transfer Dissociation Mass Spectrometry. Proc. Natl. Acad. Sci. U. S. A. 2004, 101, 9528-9533.

(25) Jones, J. W.; Sasaki, T.; Goodlett, D. R.; Tureček, F. Electron Capture in Spin-Trap Capped Peptides. An Experimental Example of Ergodic Dissociation in Peptide Cation-Radicals. J. Am. Soc. Mass Spectrom. 2007, 18, 432-444.

(26) Pepin, R; Tureček, F. Kinetic Ion Thermometers for Electron Transfer Dissociation. J. Phys. Chem. B 2015, 119, 2818-2826.

(27) Tureček, F. N-C $\alpha$ Bond Dissociation Energies and Kinetics in Amide and Peptide Radicals. Is the Dissociation a Non-Ergodic Process? J. Am. Chem. Soc. 2003, 125, 5954-5963.

(28) Tsybin, Y. O.; He, H.; Emmett, M. R.; Hendrickson, C. L.; Marshall, A. G. Ion Activation in Electron Capture Dissociation to Distinguish between N-Terminal and C-Terminal Product Ions. Anal. Chem. 2007, 79, 7596-7602.

(29) Zubarev, R. A.; Kelleher, N. L.; McLafferty, F. W. Electron Capture Dissociation of Multiply Charged Protein Cations. A Nonergodic Process. J. Am. Chem. Soc. 1998, 120, 3265-3266.

(30) Kruger, N. A.; Zubarev, R. A.; Horn, D. M.; McLafferty, F. W. Electron Capture Dissociation of Multiply Charged Peptide Cations. Int. J. Mass Spectrom. 1999, 185-187, 787-793.

(31) Zubarev, R. A. Reactions of Polypeptide Ions with Electrons in the Gas Phase. Mass Spectrom. Rev. 2003, 22, 57-77.

(32) Zubarev, R. A.; Zubarev, A. R.; Savitski, M. M. Electron Capture/Transfer Versus Collisionally Activated/Induced Dissociations: Solo or Duet? J. Am. Soc. Mass Spectrom. 2008, 19, 753-761.

(33) Savitski, M. M.; Kjeldsen, F.; Nielsen, M. L.; Zubarev, R. A. Complementary Sequence Preferences of Electron-Capture Dissociation and Vibrational Excitation in Fragmentation of Polypeptide Polycations. Angew. Chem., Int. Ed. 2006, 45, 5301-5303.

(34) Tureček, F.; Julian, R. R. Peptide Radicals and Cation Radicals in the Gas Phase. Chem. Rev. 2013, 113, 6691-6733.

(35) Zhurov, K. O.; Fornelli, L.; Wodrich, M. D.; Laskay, U. A.; Tsybin, Y. O. Principles of Electron Capture and Transfer Dissociation Mass Spectrometry Applied to Peptide and Protein Structure Analysis. Chem. Soc. Rev. 2013, 42, 5014-5030.

(36) McLuckey, S. A.; Stephenson, J. L., Jr Ion/Ion Chemistry of High-Mass Multiply Charged Ions. Mass Spectrom. Rev. 1998, 17, 369-407.

(37) Martens, J.; Berden, G.; Oomens, J. Structures of Fluoranthene Reagent Anions Used in Electron Transfer Dissociation and Proton 
Transfer Reaction Tandem Mass Spectrometry. Anal. Chem. 2016, 88, 6126-6129.

(38) Tureček, F.; Syrstad, E. A. Mechanism and Energetics of Intramolecular Hydrogen Transfer in Amide and Peptide Radicals and Cation-Radicals. J. Am. Chem. Soc. 2003, 125, 3353-3369.

(39) Zubarev, R. A.; Kruger, N. A.; Fridriksson, E. K.; Lewis, M. A.; Horn, D. M.; Carpenter, B. K.; McLafferty, F. W. Electron Capture Dissociation of Gaseous Multiply-Charged Proteins Is Favored at Disulfide Bonds and Other Sites of High Hydrogen Atom Affinity. J. Am. Chem. Soc. 1999, 121, 2857-2862.

(40) Syrstad, E. A.; Tureček, F. Toward a General Mechanism of Electron Capture Dissociation. J. Am. Soc. Mass Spectrom. 2005, 16, 208-224.

(41) Sawicka, A.; Skurski, P.; Hudgins, R. R.; Simons, J. Model Calculations Relevant to Disulfide Bond Cleavage Via Electron Capture Influenced by Positively Charged Groups. J. Phys. Chem. B 2003, 107, 13505-13511.

(42) Syrstad, E. A.; Stephens, D. D.; Tureček, F. Hydrogen Atom Adducts to the Amide Bond. Generation and Energetics of Amide Radicals in the Gas Phase. J. Phys. Chem. A 2003, 107, 115-126.

(43) Syrstad, E. A.; Tureček, F. Hydrogen Atom Adducts to the Amide Bond. Generation and Energetics of the Amino(Hydroxy)Methyl Radical in the Gas Phase. J. Phys. Chem. A 2001, 105, 1114411155 .

(44) Zubarev, R. A.; Horn, D. M.; Fridriksson, E. K.; Kelleher, N. L.; Kruger, N. A.; Lewis, M. A.; Carpenter, B. K.; McLafferty, F. W. Electron Capture Dissociation for Structural Characterization of Multiply Charged Protein Cations. Anal. Chem. 2000, 72, 563-573.

(45) Anusiewicz, I.; Berdys-Kochanska, J.; Simons, J. Electron Attachment Step in Electron Capture Dissociation (ECD) and Electron Transfer Dissociation (ETD). J. Phys. Chem. A 2005, 109, 5801-5813.

(46) Anusiewicz, I.; Berdys-Kochanska, J.; Skurski, P.; Simons, J. Simulating Electron Transfer Attachment to a Positively Charged Model Peptide. J. Phys. Chem. A 2006, 110, 1261-1266.

(47) Sobczyk, M.; Simons, J. The Role of Excited Rydberg States in Electron Transfer Dissociation. J. Phys. Chem. B 2006, 110, 75197527.

(48) Chen, X.; Tureček, F. The Arginine Anomaly: Arginine Radicals Are Poor Hydrogen Atom Donors in Electron Transfer Induced Dissociations. J. Am. Chem. Soc. 2006, 128, 12520-12530.

(49) Simons, J. Mechanisms for S-S and N-C $\alpha$ Bond Cleavage in Peptide ECD and ETD Mass Spectrometry. Chem. Phys. Lett. 2010, 484, 81-95

(50) Patriksson, A.; Adams, C.; Kjeldsen, F.; Raber, J.; van der Spoel, D.; Zubarev, R. A. Prediction of N-C Bond Cleavage Frequencies in Electron Capture Dissociation of Trp-Cage Dications by Force-Field Molecular Dynamics Simulations. Int. J. Mass Spectrom. 2006, 248, 124-135.

(51) Wodrich, M. D.; Zhurov, K. O.; Vorobyev, A.; Hamidane, H. B.; Corminboeuf, C.; Tsybin, Y. O. Heterolytic N-C $\alpha$ Bond Cleavage in Electron Capture and Transfer Dissociation of Peptide Cations. J. Phys. Chem. B 2012, 116, 10807-10815.

(52) Wodrich, M. D.; Zhurov, K. O.; Corminboeuf, C.; Tsybin, Y. O. On the Viability of Heterolytic Peptide N-C $\alpha$ Bond Cleavage in Electron Capture and Transfer Dissociation Mass Spectrometry. J. Phys. Chem. B 2014, 118, 2985-2992.

(53) Schneeberger, E.-M.; Breuker, K. Replacing $\mathrm{H}^{+}$by $\mathrm{Na}^{+}$or $\mathrm{K}^{+}$in Phosphopeptide Anions and Cations Prevents Electron Capture Dissociation. Chem. Sci. 2018, 9, 7338-7353.

(54) Zubarev, R. A.; Haselmann, K. F.; Budnik, B. A.; Kjeldsen, F.; Jensen, F. Towards an Understanding of the Mechanism of ElectronCapture Dissociation: A Historical Perspective and Modern Ideas. Eur. J. Mass Spectrom. 2002, 8, 337-349.

(55) Sobczyk, M.; Anusiewicz, I.; Berdys-Kochanska, J.; Sawicka, A.; Skurski, P.; Simons, J. Coulomb-Assisted Dissociative Electron Attachment: Application to a Model Peptide. J. Phys. Chem. A 2005, 109, 250-258.
(56) Tureček, F. Transient Intermediates of Chemical Reactions by Neutralization-Reionization Mass Spectrometry. In Modern Mass Spectrometry; Schalley, C. A., Ed.; Springer: Berlin, 2003; pp 77-129.

(57) Anusiewicz, I.; Skurski, P.; Simons, J. Refinements to the UtahWashington Mechanism of Electron Capture Dissociation. J. Phys. Chem. B 2014, 118, 7892-7901.

(58) Imaoka, N.; Houferak, C.; Murphy, M. P.; Nguyen, H. T. H.; Dang, A.; Tureček, F. Spontaneous Isomerization of Peptide Cation Radicals Following Electron Transfer Dissociation Revealed by UVVis Photodissociation Action Spectroscopy. J. Am. Soc. Mass Spectrom. 2018, 29, 1768-1780.

(59) Martens, J.; Berden, G.; Gebhardt, C. R.; Oomens, J. Infrared Ion Spectroscopy in a Modified Quadrupole Ion Trap Mass Spectrometer at the FELIX Free Electron Laser Laboratory. Rev. Sci. Instrum. 2016, 87, 103108.

(60) Kempkes, L. J. M.; Martens, J.; Grzetic, J.; Berden, G.; Oomens, J. Deamidation Reactions of Asparagine- and Glutamine-Containing Dipeptides Investigated by Ion Spectroscopy. J. Am. Soc. Mass Spectrom. 2016, 27, 1855-1869.

(61) Lucas, B.; Grégoire, G.; Lemaire, J.; Maître, P.; Ortega, J.; Rupenyan, A.; Reimann, B.; Schermann, J. P.; Desfrançois, C. Investigation of the Protonation Site in the Dialanine Peptide by Infrared Multiphoton Dissocation Spectroscopy. Phys. Chem. Chem. Phys. 2004, 6, 2659-2663.

(62) Polfer, N. C.; Oomens, J. Reaction Products in Mass Spectrometry Elucidated with Infrared Spectroscopy. Phys. Chem. Chem. Phys. 2007, 9, 3804-3817.

(63) Fung, Y. M. E.; Besson, T.; Lemaire, J.; Maitre, P.; Zubarev, R. A. Room-Temperature Infrared Spectroscopy Combined with Mass Spectrometry Distinghuishes Gas-Phase Protein Isomers. Angew. Chem., Int. Ed. 2009, 48, 8340-8342.

(64) Correia, C. F.; Balaj, P. O.; Scuderi, D.; Maitre, P.; Ohanessian, G. Vibrational Signatures of Protonated, Phosphorylated Amino Acids in the Gas Phase. J. Am. Chem. Soc. 2008, 130, 3359-3370.

(65) Frison, G.; van der Rest, G.; Tureček, F.; Besson, T.; Lemaire, J.; Maître, P.; Chamot-Rooke, J. Structure of Electron-Capture Dissociation Fragments from Charge-Tagged Peptides Probed by Tunable Infrared Multiple Photon Dissociation. J. Am. Chem. Soc. 2008, 130, 14916-14917.

(66) Shaffer, C. J.; Martens, J.; Marek, A.; Oomens, J.; Tureček, F. Photoleucine Survives Backbone Cleavage by Electron Transfer Dissociation. A near-UV Photodissociation and Infrared Multiphoton Dissociation Action Spectroscopy Study. J. Am. Soc. Mass Spectrom. 2016, 27, 1176-1185.

(67) Moss, C. L.; Chamot-Rooke, J.; Nicol, E.; Brown, J.; Campuzano, I.; Richardson, K.; Williams, J. P.; Bush, M. F.; Bythell, B.; Paizs, B.; Tureček, F. Assigning Structures to Gas-Phase Peptide Cations and Cation-Radicals. An Infrared Multiphoton Dissociation, Ion Mobility, Electron Transfer, and Computational Study of a Histidine Peptide Ion. J. Phys. Chem. B 2012, 116, 34453456.

(68) Han, H.; Xia, Y.; McLuckey, S. A. Ion Trap Collisional Activation of $\mathrm{c}$ and $\mathrm{z}^{\bullet}$ Ions Formed Via Gas-Phase Ion/Ion ElectronTransfer Dissociation. J. Proteome Res. 2007, 6, 3062-3069.

(69) Grzetic, J.; Oomens, J. Structure of Anionic c-Type Peptide Fragments Elucidated by IRMPD Spectroscopy. Int. J. Mass Spectrom. 2012, 316-318, 216-226.

(70) Bythell, B. J. C C $_{\alpha}$ Hydrogen Atom Transfer in Post-Cleavage Radical-Cation Complexes: Short and Steep Versus Long Winding Road. J. Phys. Chem. A 2014, 118, 10797-10803.

(71) Pepin, R.; Laszlo, K. J.; Peng, B.; Marek, A.; Bush, M. F.; Tureček, F. Comprehensive Analysis of Gly-Leu-Gly-Gly-Lys Peptide Dication Structures and Cation-Radical Dissociations Following Electron Transfer: From Electron Attachment to Backbone Cleavage, Ion-Molecule Complexes, and Fragment Separation. J. Phys. Chem. A 2014, 118, 308-324.

(72) Schennach, M.; Breuker, K. Probing Protein Structure and Folding in the Gas Phase by Electron Capture Dissociation. J. Am. Soc. Mass Spectrom. 2015, 26, 1059-1067. 
(73) Martens, J.; Grzetic, J.; Berden, G.; Oomens, J. Structural Identification of Electron Transfer Dissociation Products in Mass Spectrometry Using Infrared Ion Spectroscopy. Nat. Commun. 2016, $7,11754$.

(74) Frisch, M. J.; Trucks, G. W.; Schlegel, H. B.; Scuseria, G. E.; Robb, M. A.; Cheeseman, J. R.; Scalmani, G.; Barone, V.; Mennucci, B.; Petersson, G. A.; Nakatsuji, H.; Caricato, M.; Li, X.; Hratchian, H. P.; Izmaylov, A. F.; Bloino, J.; Zheng, G.; Sonnenberg, J. L.; Hada, M.; Ehara, M.; Toyota, K.; Fukuda, R.; Hasegawa, J.; Ishida, M.; Nakajima, T.; Honda, Y.; Kitao, O.; Nakai, H.; Vreven, T.; Montgomery, J., J.A; Peralta, J. E.; Ogliaro, F.; Bearpark, M.; Heyd, J. J.; Brothers, E.; Kudin, K. N.; Staroverov, V. N.; Kobayashi, R.; Normand, J.; Raghavachari, K.; Rendell, A.; Burant, J. C.; Iyengar, S. S.; Tomasi, J.; Cossi, M.; Rega, N.; Millam, N. J.; Klene, M.; Knox, J. E.; Cross, J. B.; Bakken, V.; Adamo, C.; Jaramillo, J.; Gomperts, R.; Stratmann, R. E.; Yazyev, O.; Austin, A. J.; Cammi, R.; Pomelli, C.; Ochterski, J. W.; Martin, R. L.; Morokuma, K.; Zakrzewski, V. G.; Voth, G. A.; Salvador, P.; Dannenberg, J. J.; Dapprich, S.; Daniels, A. D.; Farkas, O.; Foresman, J. B.; Ortiz, J. V.; Cioslowski, J.; Fox, D. J. Gaussian09, revision D01. Gaussian, Inc.: Wallingford, CT, 2009.

(75) Case, D. A.; Darden, T.; Cheatham, T. E., III; Simmerling, C.; Wang, J.; Duke, R. E.; Luo, R.; Walker, R. C.; Zhang, W.; Merz, K. M.; Roberts, B. P.; Hayik, S.; Roitberg, A.; Seabra, G.; Swails, J.; Goetz, A. W.; Kolossváry, I.; Wong, K. F.; Paesani, F.; Vanicek, J.; Wolf, R. M.; Liu, J.; Wu, X.; Brozell, S. R.; Steinbrecher, T.; Gohlke, H.; Cai, Q.; Ye, X.; Wang, J.; Hsieh, M.-J.; Cui, G.; Roe, D. R.; Mathews, D. H.; Seetin, M. G.; Salomon-Ferrer, R.; Sagui, C.; Babin, V.; Luchko, T.; Gusarov, S.; Kovalenko, A.; Kollman, P. A. Amber; University of California, San Francisco, 2012.

(76) Martens, J.; Grzetic, J.; Berden, G.; Oomens, J. Gas-Phase Conformations of Small Polyprolines and Their Fragment Ions by Irmpd Spectroscopy. Int. J. Mass Spectrom. 2015, 377, 179-187. 